\title{
Albedo-induced radiative forcing from mountain pine beetle outbreaks in forests, south-central Rocky Mountains: magnitude, persistence, and relation to outbreak severity
}

\author{
M. Vanderhoof ${ }^{1}$, C. A. Williams ${ }^{1}$, Y. Shuai ${ }^{2}$, D. Jarvis ${ }^{1}$, D. Kulakowski ${ }^{1}$, and J. Masek ${ }^{3}$ \\ ${ }^{1}$ Graduate School of Geography, Clark University, 950 Main Street, Worcester MA 01610, USA \\ ${ }^{2}$ Earth Resources Technology, Inc. at NASA/GSFC, Greenbelt, Maryland 20771, USA \\ ${ }^{3}$ NASA/GSFC, Greenbelt, Maryland 20771, USA \\ Correspondence to: M. Vanderhoof (mevanderhoof@ clarku.edu)
}

\begin{abstract}
Mountain pine beetle (MPB) outbreaks in North America are widespread and have potentially persistent impacts on forest albedo and associated radiative forcing. This study utilized multiple data sets, both current and historical, within lodgepole pine stands in the south-central Rocky Mountains to quantify the full radiative forcing impact of outbreak events for decades after outbreak $(0-60 \mathrm{yr})$ and the role of outbreak severity in determining that impact. Change in annual albedo and radiative forcing peaked at 14$20 \mathrm{yr}$ post-outbreak $\left(0.06 \pm 0.006\right.$ and $-0.8 \pm 0.1 \mathrm{~W} \mathrm{~m}^{-2}$, respectively) and recovered to pre-outbreak levels by $30-40 \mathrm{yr}$ post-outbreak. Change in albedo was significant in all four seasons, but strongest in winter with the increased visibility of snow (radiative cooling of $-1.6 \pm 0.2 \mathrm{~W} \mathrm{~m}^{-2}$, $-3.0 \pm 0.4 \mathrm{~W} \mathrm{~m}^{-2}$, and $-1.6 \pm 0.2 \mathrm{~W} \mathrm{~m}^{-2}$ for $2-13,14-20$ and $20-30 \mathrm{yr}$ post-outbreak, respectively). Change in winter albedo and radiative forcing also increased with outbreak severity (percent tree mortality). Persistence of albedo effects are seen as a function of the growth rate and species composition of surviving trees, and the establishment and growth of both understory herbaceous vegetation and tree species, all of which may vary with outbreak severity. The establishment and persistence of deciduous trees was found to increase the temporal persistence of albedo effects. MPBinduced changes to radiative forcing may have feedbacks for regional temperature and the hydrological cycle, which could impact future MPB outbreaks dynamics.
\end{abstract}

\section{Introduction}

Current outbreaks of bark beetles (Coleoptera: Curculionidae, Scolytinae) in western North America are some of the largest and most severe in recorded history (Bentz et al., 2009). Since 1997, more than 41.7 million acres have been affected by bark beetles in the western United States and more than 6.6 million acres in Colorado alone (USFS, 2011). Outbreaks result in tree mortality, temporarily reducing live tree density and changing stand reflectivity of shortwave radiation. Tree mortality has multiple stages, with the needles of a host lodgepole pine tree typically turning red within twelve months of being attacked (red attack stage) and falling off within three years (gray attack stage) (Mitchell and Preisler, 1998). In general, snags begin to fall five years after stand death, with snag fall peaking after ten to fifteen years, although this may vary regionally (Mitchell and Preisler, 1998; Huggard and Lewis, 2007). In recent Colorado outbreaks (1996 to present), mountain pine beetles (MPB) (Dendroctonus ponderosae) have reduced the live basal area of lodgepole pine (Pinus contorta)-dominated forests by $70 \%$, on average (Klutsch et al., 2009). The current extent and high severity (percent tree mortality) of these recent MPB outbreaks has been attributed to warmer summer and winter temperatures and drought conditions associated with regional climate change (Berg et al., 2006; Raffa et al., 2008). Temperature and precipitation trends have increased over-winter survival of beetle populations, increased the rate of reproduction and maturation, and created drought-induced stress in tree hosts (Berg et al., 2006; Raffa et al., 2008).

Terrestrial albedo directly influences the total shortwave energy input into the biosphere and is an important deter- 


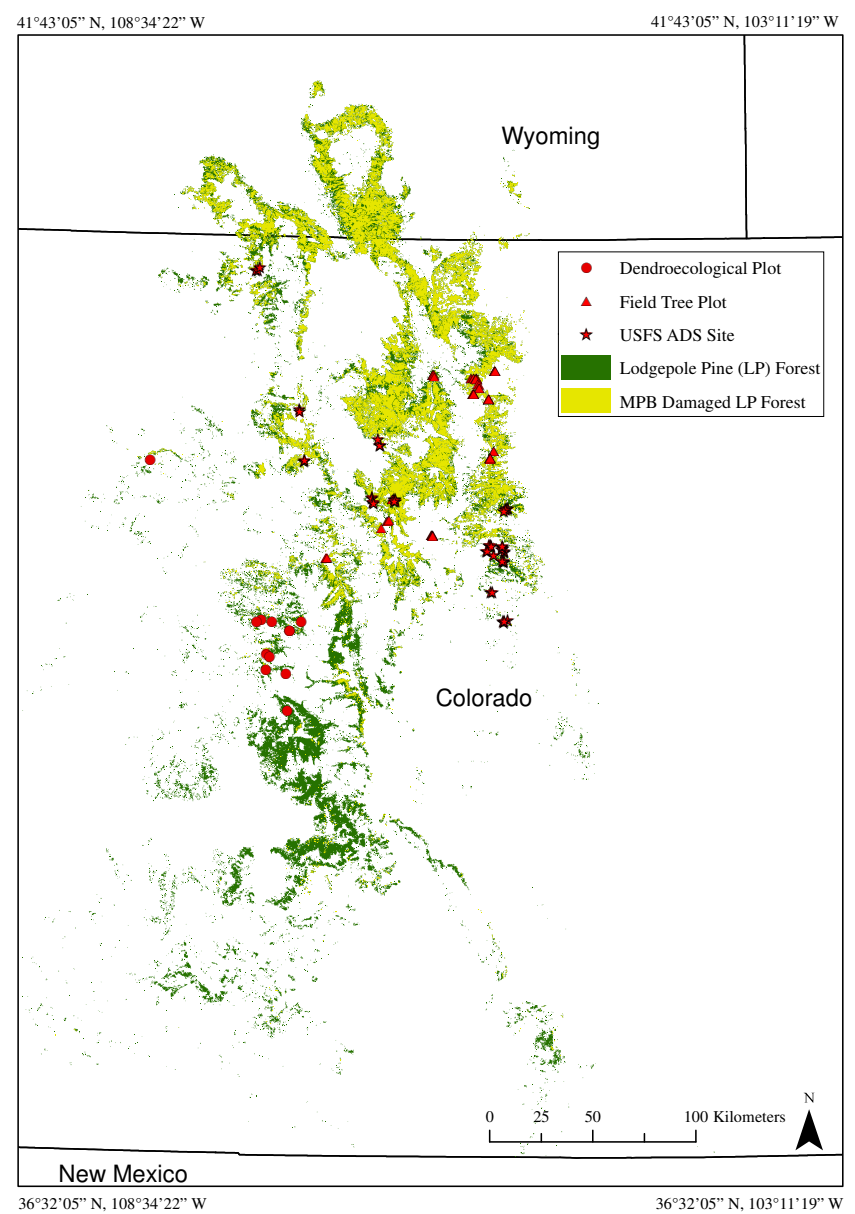

Fig. 1. Plot locations for field tree plots, dendroecological plots and USFS ADS sites.

minant of the earth's surface energy balance with attendant impacts on the biosphere and climate (Zhang et al., 1995). Reductions in canopy cover due to disturbance events cause changes in forest structure and composition that can have profound impacts on surface albedo. These impacts can outweigh the carbon dioxide and volatile organic carbon (e.g., terpene) emission consequences of a mortality event, resulting in an albedo-driven change in radiative forcing (Betts, 2000; Randerson et al., 2006; Spracklen et al., 2008). In the growing season a site may experience a decline in albedo post-disturbance with the increased visibility of bare soil (Bourque et al., 1995). With the establishment of vegetation ground cover, albedo values are typically either elevated or similar to pre-disturbance levels (McCaughey, 1987; Bourque et al., 1995; Gholz and Clark, 2002). Within boreal and high-elevation regions, forest loss or tree mortality can result in a significant increase in yearly albedo due to the increased visibility of snow (Betts et al., 2000; Bala et al., 2007). For evergreen coniferous forests that may be dominated by deciduous species in early successional stages, annual changes in albedo can persist for many more decades post-disturbance, relative to the establishment of evergreen species (Randerson et al., 2006). On an annual basis, an elevated albedo increases shortwave reflectance and reduces net radiation, which may result in a local annual cooling effect (Betts, 2000; Claussen et al., 2001; Bala et al., 2007). In addition to more direct climate effects (e.g., radiative forcing), changes in albedo also have potential local consequences for the hydrological cycle. Earlier snowmelt, due to increased canopy shortwave transmission, as well as increased snow accumulation, from changes in stand structure, have been documented post-outbreak (Bewley et al., 2010; Boon, 2012; Pugh and Small, 2012). Changes to snow accumulation and snowmelt dynamics, in turn, can result in temporary increases in soil moisture (Clow et al., 2011) and stream flow (Bethlahmy, 1975; Potts 1984).

Despite wide recognition of the large extent and severity of recent MPB outbreaks, an assessment of the decadal persistence of albedo and radiative forcing effects, as well as an exploration of the impact of outbreak severity on those effects, are both still lacking. Existing studies have documented a decrease in winter albedo in the early attack stages due to needle and litter accumulation on snow (Winkler et al., 2010; Pugh and Small, 2012) and an increase in winter albedo after needle fall, presumably due to the increased visibility of snow (O'Halloran et al., 2012; Vanderhoof et al., 2013). The persistence of winter albedo changes in existing studies has been limited to $\sim 15 \mathrm{yr}$ post-outbreak when albedo change remains large. Furthermore, the variability in outbreak severity has largely been ignored. This study combines field data on tree attributes, historic US Forest Service (USFS) aerial surveys of insect damage and dendroecological data to address the following research questions: How does albedo change with attack severity and season? What is the longevity of these albedo impacts and how do these impacts translate into radiative forcing? And can we use vegetation data to explore how outbreak severity may affect the temporal persistence of a change to albedo? Although the epidemic has slowed in many areas of Colorado and Wyoming, due potentially to the depletion of available host trees, the temporal lag in needle loss, snag fall and forest regrowth implies a prolonged impact on forest structure, albedo, and potentially climate.

\section{Methods}

\subsection{Study area}

The study area was restricted to healthy and MPB-damaged lodgepole-pine-dominated forests within the Colorado and southern Wyoming Rocky Mountains (Fig. 1). Lodgepole pine is found throughout the western United States and northwestern Canada on the lower slopes and valleys above the foothills at elevations between 2100 and $2900 \mathrm{~m}$. It occurs in pure stands, either dense or open, and in mixed stands with 
other species. Lodgepole pine trees are relatively shade intolerant and many have serotinous cones, adaptations that allow for establishment after a severe forest fire (Kaufmann et al., 2008). Lodgepole pine seedlings tend to grow faster than spruce or fir seedlings and can dominate stands in early successional stages, assuming favorable site conditions. If aspen is present, its sprouting ability can lead to a co-dominance of aspen and lodgepole or to aspen dominating early successional stages, prior to giving way to slower-growing lodgepole pine. Without fire, older lodgepole pine stands can experience in-growth of other species, including Engelmann spruce (Picea engelmannii) and subalpine fir (Abies lasiocarpa), if those species are present and if site conditions are favorable (Kaufmann et al., 2008). Non-serotinous cones also allow for the regeneration of lodgepole pine post-MPB outbreak (Axelson et al., 2010; Teste et al., 2011).

Based on climatological records from Estes Park, CO (2365 m elevation), mean annual precipitation is $540 \mathrm{~mm}$, while the average low and high temperature is $-9^{\circ} \mathrm{C}$ in January and $25^{\circ} \mathrm{C}$ in July, respectively. Topography and thus microclimate varies substantially within the study area. Locations of past fires (1984-2011) were derived from Monitoring Trends in Burn Severity (MTBS) data and were masked out (Eidenshink et al., 2007).

\subsection{Data}

Albedo was primarily derived from the Moderate Resolution Imaging Spectroradiometer (MODIS) Collection 5 BRDF/Albedo 16-day $500 \mathrm{~m}$ product (MCD43A3), which couples a semi-empirical, RossThick-LiSparse kernel-driven bidirectional reflectance distribution function (BRDF) model with multi-date, cloud-free, atmospherically corrected surface reflectance to determine the anisotropy of global land surfaces at a $500 \mathrm{~m}$ spatial resolution (Schaaf et al., 2002). Steep topography, such as that in the south-central Rocky Mountains, has the potential to bias albedo values. To minimize this source of bias, white-sky albedo broadband was used as it is independent of view and solar angles and thus more comparable across both mountainous regions and temporally (Gao et al., 2005). The MODIS albedo data utilized were limited to 2012 and winter 2013, in order to minimize differences between the satellite spectral information and field observations (collected in the summer of 2012). To capture seasonal albedo variation, we examined shortwave $(0.3-$ $5.0 \mu \mathrm{m}$ ) broadband white-sky albedo (WSA) for all 52 dates available between 1 January 2012 and 26 February 2013. Within each image, we rejected all observations with cloud cover, bad quality or fill values based on data quality flags. NIR white-sky broadband albedo was also tested, but similarity in findings to SW white-sky broadband albedo led to its exclusion. The accuracy of the MODIS Collection 5 shortwave albedo is reported as 0.05 but is generally $<0.03$ (Roman et al., 2009; Wang et al., 2010).
In addition to the MODIS albedo data, select images of albedo derived from Landsat-7 ETM+ were also utilized (p34, r32). Snow-free Landsat albedo images (DOY 170, 218 and 266 2012) were derived using the methodology described in Shuai et al. (2011), which integrates land-coverbased high-quality BRDFs over the homogenous region, extracted from MCD43A operational products, with Landsat surface reflectance to calculate spectral and broadband white- and black-sky albedo. Snow-cover Landsat shortwave broadband albedo images (DOY 012, 026 2012) were derived in terms of concurrent MCD43A snow BRDFs and the albedo-to-reflectance ratios for each determined snowcover pixel by MOD10 snow mapping algorithm (Hall et al., 2002). It should be noted that the snow-cover Landsat albedo methodology is still in development and that this was an experimental application of the method. Results derived using snow-cover Landsat albedo images are provided only for comparison to findings from the usage of the MODIS albedo data set.

Data on locations of MPB outbreaks were derived from three sources: (1) field data on tree attributes collected in plots (63 sites), (2) historic USFS Aerial Detection Surveys (USFS ADS) (46 sites), and (3) field-based dendroecological plots (11 sites) (Table 1, Fig. 1). Field-collected tree plot data were collected in lodgepole-pine-dominated stands from 18 June to 20 July 2012, within $900 \mathrm{~m}^{2}$ plots $\left(56700 \mathrm{~m}^{2}\right.$ total). Plots were targeted to be representative of (1) the surrounding $500 \mathrm{~m} \times 500 \mathrm{~m}$ area, (2) a severity spectrum (from none to severe) of mountain pine beetle outbreak, and (3) a spectrum of time since attack (green attack, red attack and gray attack stages). Although plots were not restricted to pure lodgepole pine stands, the plots were on average $93 \%$ lodgepole pine. Within each plot, each tree was identified to the species level, its diameter measured $(\mathrm{dbh}>7.5 \mathrm{~cm})$, and recorded as non-attacked (no evidence of beetle presence), green attack stage (exit holes and pitch tubes present but needles still green), red attack stage (exit holes and pitch tubes present and needles red) or gray attack stage (exit holes and pitch tubes present and needles absent), or unknown dead (needles absent, but no evidence of beetle damage). Sapling and seedling $(\mathrm{dbh}<7.5 \mathrm{~cm})$ abundances and species composition were sampled in two $25 \mathrm{~m}^{2}$ subplots within each plot. Mean canopy height was measured using a clinometer, canopy cover was measured using a densitometer, litter depth was measured using a ruler in soil pits, and understory cover (vegetation, litter, bare rock) was visually estimated. Plots were categorized by attack stage (healthy, red, gray), where attacked plots were categorized as red if the majority of attacked trees were in the red attack stage, or gray if the majority of the attacked trees were in the gray attack stage. The plots were also categorized by severity, using percent dead trees, where low (14-40\% mortality), medium (41$57 \%$ mortality) and high ( $>58 \%$ mortality) categories each contained an equivalent number of plots. Percent dead trees ranged from $<1$ to $88 \%$ with a mean percent mortality of 
Table 1. The number and source of MPB outbreak locations utilized by time interval or time since MPB outbreak.

\begin{tabular}{lllr}
\hline Time interval & Number of sites/source & Number of sites/source & Total \# \\
\hline Healthy & 14/2012 tree plots & & 14 \\
$1-3 \mathrm{yr}$ & $10 / 2012$ tree plots & & 10 \\
$4-13 \mathrm{yr}$ & 33/2012 tree plots & & 33 \\
$14-20 \mathrm{yr}$ & 6/2012 tree plots & 14/USFS ADS sites & 20 \\
$21-30 \mathrm{yr}$ & 10/2009 dendro plots & 9/USFS ADS sites & 19 \\
$31-40 \mathrm{yr}$ & 1/2008 dendro plot & 18/USFS ADS sites & 19 \\
$50-60 \mathrm{yr}$ & 5/USFS ADS sites & & 5 \\
& & Total & 120 \\
\hline
\end{tabular}

$41 \%$. A potential bias in the albedo signal due to differences in scale between the field data and MODIS data may occur. To correct for this potential bias, the MODIS pixel extent for each field plot was reviewed using 2011 National Agriculture Imagery Program (NAIP) imagery to check for consistency of forest cover and damage patterns. Plots within MODIS pixels that were $<75 \%$ coniferous forest cover were removed from the analysis. Because no such scale issue occurred with the Landsat pixels, all field plots were included in the analysis.

The primary source for historic ( $>16 \mathrm{yr}$ since outbreak) MPB outbreak locations was geo-referenced USFS Region 2 ADS maps (1956-1987). These maps were periodically created by expert surveyors to record "new damage" polygons during flown surveys. Although an absence of a polygon does not necessarily indicate true absence due to the incomplete spatial nature of these surveys, a drawn polygon provides high confidence of the presence of an outbreak. To reduce potential error regarding the location of these outbreaks, historic outbreak plot locations were located at the center of "damage" polygons larger than a MODIS pixel. Additionally, polygons of historic outbreaks were eliminated from consideration if they (1) overlapped with damage polygons identified in later USFS Region ADS maps (1994-2011), (2) did not occur within lodgepole-dominated forests as defined by multiple USFS forest layers, or (3) showed inconsistent $(<75 \%)$ forest cover using aerial imagery (2011 USDA NAIP imagery). In addition, a disproportionate number of downed trees, relative to a typical mature forest, were observed using aerial imagery within most historic damage locations, corroborating past outbreaks.

Additional historic MPB outbreaks were located using dendroecological methods that have been previously tested (Heath and Alfaro, 1990; Alfaro et al., 2010) and applied (Axelson et al., 2009; Kulakowski and Jarvis, 2011; Kulakowski et al., 2012) to lodgepole pine stands to reconstruct stand disturbance history in this and other regions. Eleven lodgepole pine-dominated sites were randomly selected for dendroecological reconstruction of MPB outbreaks (Kulakowski et al., 2012; Jarvis et al., 2014). In each stand increment cores were collected from living host and non-host and dead host trees. Dead host trees were only cored if MPB larval galleries were present under the remaining bark. These cores were used to derive dates of stand origin, tree mortality and releases (abrupt two-fold increases in ring width sustained for more than $10 \mathrm{yr}$ ). Additional methodological details are provided in Kulakowski et al. (2012). Data were collected in summer of 2008 (Kulakowski et al., 2012) and summer of 2009 (Jarvis et al., 2014). Similar to our tree plot data, the MODIS pixel extent for each dendroecological plot was reviewed using 2011 NAIP imagery to check for consistency of forest cover. Plots within MODIS pixels that were $<75 \%$ forest were removed from the analysis. Plot locations were also checked for agreement with recent (2009-2011) outbreaks recorded in the USFS ADS data.

\subsection{Analysis}

Albedo was expressed as the change in albedo from the within-scene "healthy" lodgepole pine forest. Healthy stands were derived from fourteen non-attacked 2012 tree plot locations. Change in albedo was averaged by time interval (1-3, 4-13, 14-20, 21-30, 31-40, and 50-60 yr since disturbance) and season (winter $=$ December-February; spring $=$ MarchMay; summer = June-August; fall = September-November) to derive seasonal curves for change in albedo with time since outbreak start. The width of the time intervals was based on our confidence in deriving an accurate year of outbreak. The time intervals of 41-50 and > 60 yr since MPB outbreak were not included due to small sample sizes. To assess the role of attack severity, gray-attack-dominated tree plots were categorized by percent tree mortality, where thresholds between categories were determined using quantiles. Pearson pair-wise correlations and paired $t$ tests were conducted using SPSS Statistics (IBM Corporation, Armonk, NY).

\subsection{Radiative forcing}

We defined the net radiative forcing as the mean annual change in reflected shortwave radiation at the top of the atmosphere (TOA) resulting from changes in surface albedo (Hansen et al., 1997). The TOA radiative forcing was calculated using the "radiative kernel" technique, in which a ra- 

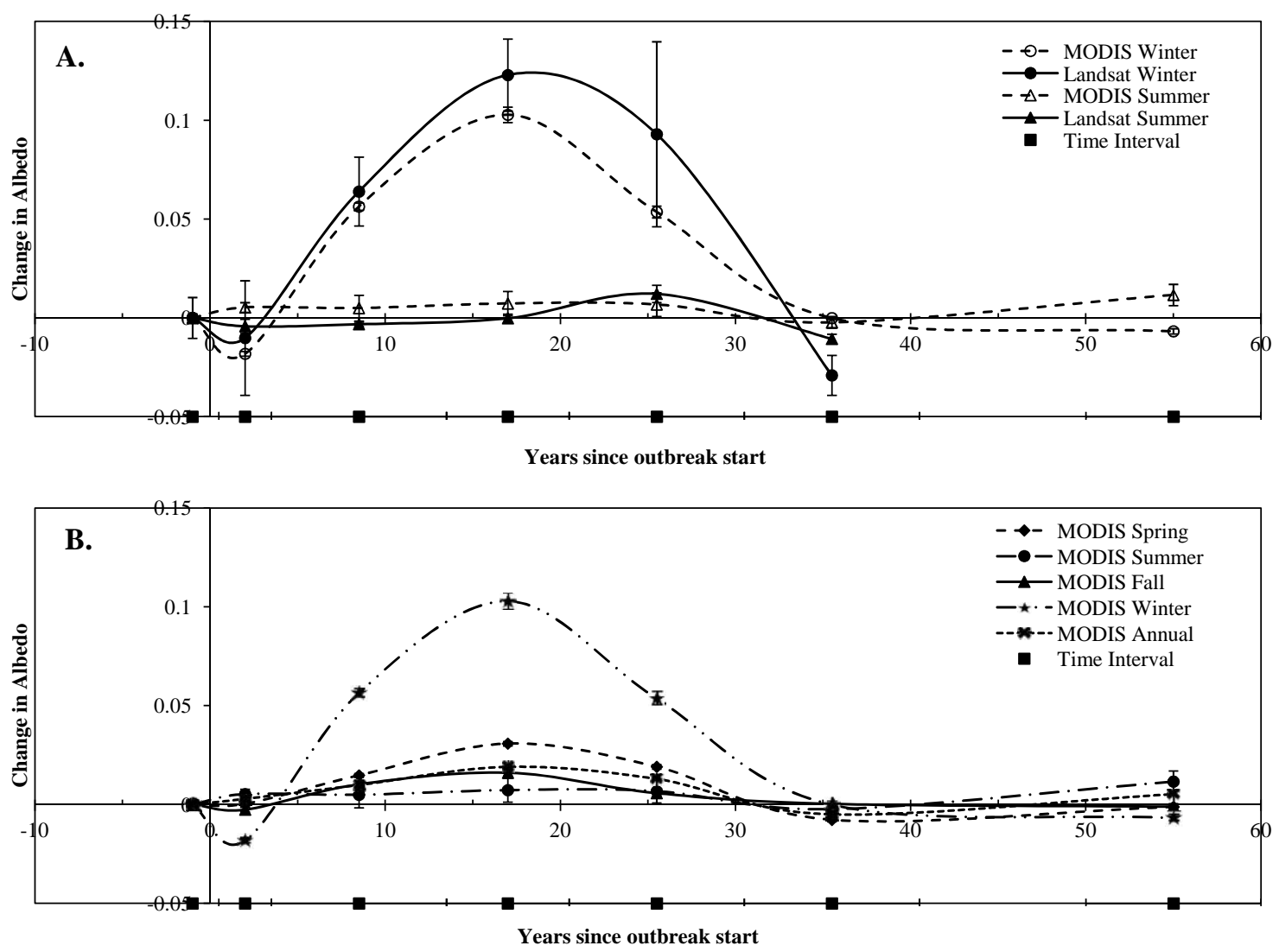

Fig. 2. (A) The MODIS versus Landsat change in winter and summer albedo with years since outbreak start. (B) The seasonal trend in change in albedo with years since outbreak start as derived from MODIS albedo. The time interval line indicates the number of years each point is averaged over. Error bars indicate plus and minus standard error.

diative kernel was derived from a radiative transfer algorithm and climate parameters to quantify the top-of-atmosphere radiative flux response to changes in a feedback variable (e.g., albedo) (Soden et al., 2007). In this case the kernel was used to translate changes in monthly average surface albedo, relative to "healthy forest" values, into changes to TOA radiative fluxes. The kernel, originally provided at $2.5^{\circ}$ resolution, was resampled to $1^{\circ}$ resolution to better match the spatial extent of the study area. The kernel $(\mathrm{K})$ was produced using the offline radiative transfer model from the National Center for Atmospheric Research (NCAR) Community Atmospheric Model version 3 (Collins et al., 2006) as described in Shell et al. (2008), and reported as the radiative forcing response to a 0.01 change in albedo, where

$\Delta \mathrm{F}_{\mathrm{TOA}}=\Delta \propto * \mathrm{~K}^{\propto}$,

where $\propto$ is the land surface shortwave albedo. A $5 \%$ uncertainty (per product) was assumed for the MODIS albedo and the radiative kernels. We implemented a conservative assumption of non-random error propagation for which uncertainty was combined as the product of those for albedo and radiative kernels. This method of uncertainty propagation is analogous to an IPCC Tier 1 uncertainty (IPCC, 2000).

\section{Results}

After MPB outbreak, an annual increase in MODIS albedo peaked at $14-20 \mathrm{yr}$ with snag fall $(0.06 \pm 0.006)$ before transitioning to a minor, non-significant change in albedo $(-0.01 \pm 0.003$ and $0.001 \pm 0.003)$, relative to non-attacked stands, by $30-40 \mathrm{yr}$ and $50-60 \mathrm{yr}$, respectively (Fig. 2). MODIS albedo of attacked stands was significantly higher than in non-attacked stands in all seasons from 4 to $30 \mathrm{yr}$ post-outbreak $(p<0.01)$, with evidence of a slight decline in the first three years post-attack in fall, winter, and summer seasons $(p<0.01)$. No significant difference between non-attacked stands and attacked stands was seen 30-40 or $50-60 \mathrm{yr}$ since attack, presumably due to the recovery of vegetation cover. The same was seen with Landsat data, for which winter and summer albedo was significantly higher $4-30 \mathrm{yr}$ since disturbance relative to non-attacked stands $(p<0.01)$. The increase in albedo post-outbreak peaked during winter months, with the increased visibility of snow. Change to winter MODIS albedo was $0.06 \pm 0.002$, $0.10 \pm 0.004$, and $0.05 \pm 0.003$, for $4-13,14-20$ and 20 $30 \mathrm{yr}$ post-outbreak, respectively (Fig. 2$)(p<0.01)$. Winter findings for Landsat albedo were not significantly differ- 


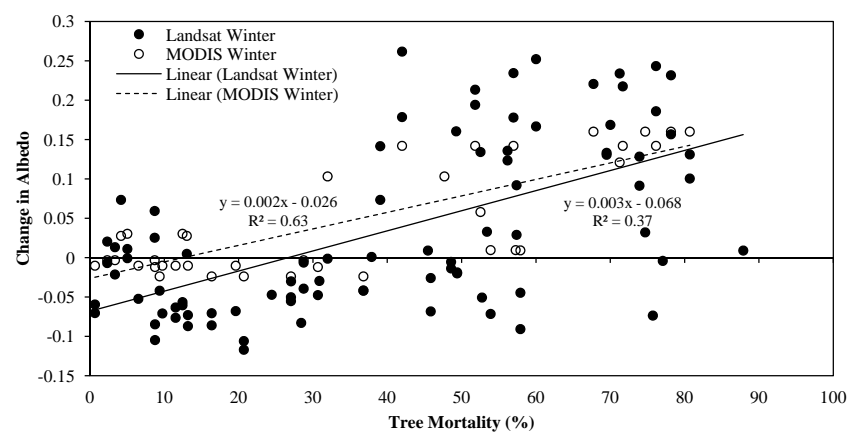

Fig. 3. Change in winter albedo with MPB outbreak severity, defined as percent tree mortality, for outbreaks $4-13$ yr in age (gray attack stage).

ent from those for MODIS for all time intervals except 30$40 \mathrm{yr}$, when Landsat showed a reduction in albedo, relative to non-attacked stands, not seen in MODIS $(p<0.01)$. This localized reduction in albedo, relative to non-attacked stands, could be due to high tree densities, a characteristic often observed in early successional stands before natural thinning occurs with tree and stand maturation.

Using only gray-attack-dominated tree plot data (4-13 yr since disturbance), change in albedo by season was examined as a function of percent tree mortality. A strong relationship was observed during winter months, with the increase in albedo rising with increased tree mortality for both MODIS $\left(y=0.0021 \times-0.026, R^{2}=0.63, p<0.01\right)$ and Landsat $\left(y=0.0026 \times-0.068, R^{2}=0.37, p<0.05\right)$ data sources (Fig. 3). The relationship between MODIS or Landsat albedo and percent tree mortality was weaker for spring $(y=0.0005 \times-0.006, R=0.63)$, summer (MODIS: $y=$ $0.0002 \times-0.002, R^{2}=0.26$, Landsat: $y=0.0002 \times-0.01$, $\left.R^{2}=0.19\right)$ and fall $\left(y=0.0003 \times-0.004, R^{2}=0.59\right)$ seasons, but still statistically significant $(p<0.01)$ (Fig. 4$)$.

These changes in albedo translated into sizeable TOA radiative forcing. Radiative forcing peaked during winter months, with an observed radiative cooling of $\quad-1.6 \pm 0.2 \mathrm{~W} \mathrm{~m}^{-2}, \quad-3.0 \pm 0.4 \mathrm{~W} \mathrm{~m}^{-2}, \quad$ and $-1.6 \pm 0.2 \mathrm{~W} \mathrm{~m}^{-2}$ for $2-13,14-20$ and $20-30 \mathrm{yr}$ postoutbreak, respectively (Fig. 5). Annual radiative cooling peaked at $14-20 \mathrm{yr}$ post-outbreak at $-0.8 \pm 0.1 \mathrm{~W} \mathrm{~m}^{-2}$. Using only gray-attack-dominated tree plot data (4-13 yr post-outbreak), seasonal and annual radiative forcing were quantified by attack severity. As would be expected, seasonal and annual radiative forcing increased with increasing attack severity. Winter radiative forcing was $0.2 \pm 0.03 \mathrm{~W} \mathrm{~m}^{-2}$, $-1.8 \pm 0.2 \mathrm{~W} \mathrm{~m}^{-2}$ and $-2.3 \pm 0.3 \mathrm{~W} \mathrm{~m}^{-2}$ for low-, medium- and high-severity outbreaks, respectively (Fig. 5). A large increase in radiative cooling occurred between low (10-30\% tree mortality) and medium (30-57\% tree mortality) outbreak severity, with a minor change between medium and high (57-88\% tree mortality) outbreak severity, suggesting that the relationship between radiative forcing

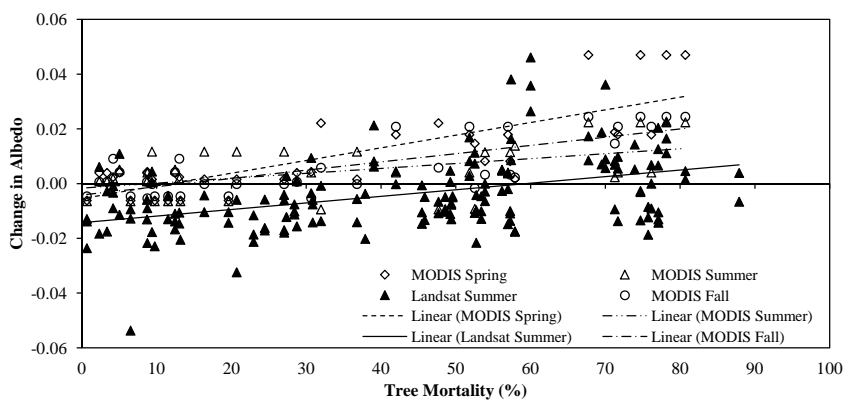

Fig. 4. Change in spring, summer and fall albedo with MPB outbreak severity, defined as percent tree mortality, for outbreaks 4 to $13 \mathrm{yr}$ in age (gray attack stage). Linear regression lines shown for each season.

and outbreak severity may exhibit a threshold rather than linear relationship. A shift in the relationship between albedo and percent tree mortality was observed at $\sim 40-50 \%$ tree mortality in Fig. 3. This threshold could be related to shadows of remaining live trees masking the change in albedo for low-severity outbreaks.

For gray-attack-dominated tree plots (4-13 yr since outbreak) the post-outbreak change in MODIS albedo was most strongly explained by the percent tree mortality (winter, $R=0.87$; fall, $R=0.83, p<0.01$ ) or number of dead trees (spring, $R=0.86$; summer, $R=0.63, p<0.01$ ) in a plot. Similarly, change in Landsat albedo was most strongly explained by the percent tree mortality (winter, $R=0.65, p=$ 0.02 ; summer, $R=0.55, p<0.01$ ). The persistence of this change in albedo, or the rate of forest regrowth, in turn, is typically a function of two mechanisms (which can cooccur): (1) the growth and reorganization of existing vegetation (e.g., advance regeneration), and/or (2) the recruitment of new vegetation (McCarthy, 2001). Given that the mortality event is targeted at lodgepole pine, the reorganization of existing vegetation can dramatically shift the forest species composition if other species are present. The remaining trees will temporarily dominate the canopy, and their size and growth rates will influence the rate of albedo recovery. Within the 2012 tree plots, a shift in live tree species composition was observed between the non-attacked and attacked plots. Within healthy stands, lodgepole pine comprised an average of $93 \%$ of trees, while within damaged plots this percent was reduced to $76 \%$. The remaining trees $(20 \%)$ within damaged plots were dominated by other coniferous species, principally Douglas fir (Pseudotsuga menziesii) and ponderosa pine (Pinus ponderosa).

In addition to the species composition of existing vegetation, the species composition of newly recruited seedlings/saplings is also important to consider, as a stand's coniferous versus deciduous trajectory can shorten or prolong changes to winter albedo, respectively (Randerson et al., 2006). Within the 2012 tree plots, attacked plots exhibited a similar (non-significantly different) seedling/sapling stem 

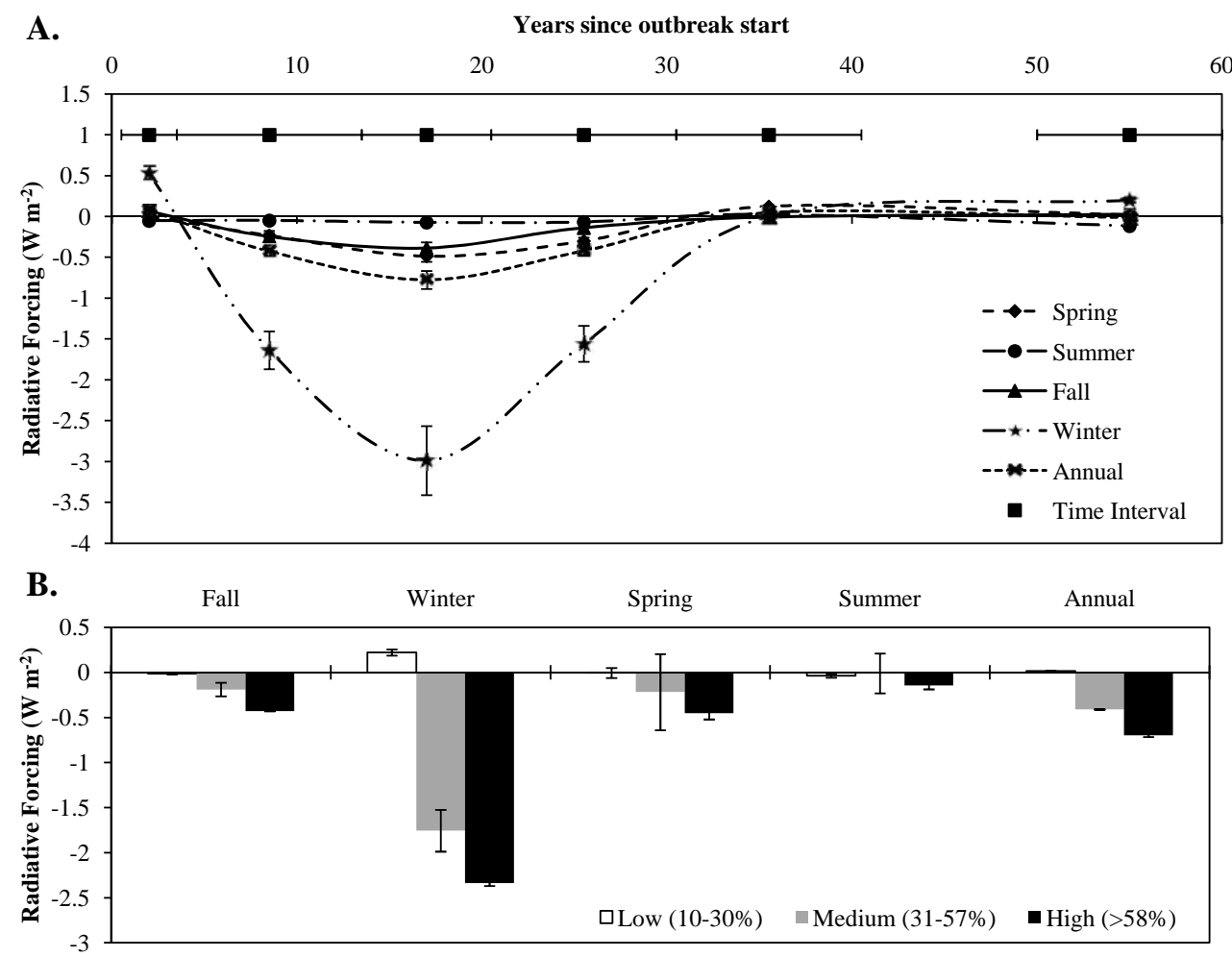

Fig. 5. (A) Seasonal pattern in radiative forcing with years since outbreak start, as derived from MODIS albedo. The time interval line indicates the number of years each point is averaged over. Error bars represent forcing uncertainty. (B) Seasonal pattern in radiative forcing with outbreak severity (\% tree mortality), where severity forcing is for gray attack stands (4-13 yr since outbreak start). Error bars represent plus and minus standard error.

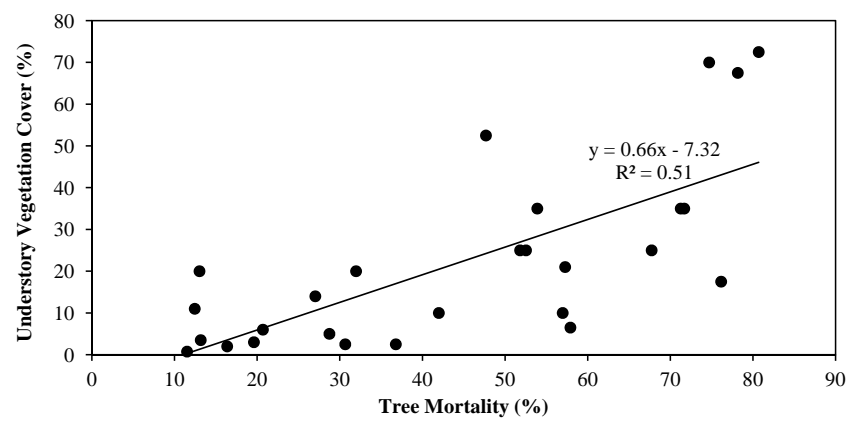

Fig. 6. Understory vegetation cover as a function of post-outbreak percent tree mortality, within gray-attack-dominated (4-13 yr since outbreak start) field tree plots.

density $\left(0.44 \pm 0.08\right.$ stems $\left.\mathrm{m}^{-2}\right)$ relative to healthy plots $\left(0.60 \pm 0.17\right.$ stems $\left.^{-2}\right)$. Healthy and damaged plots exhibited similar proportions of lodgepole pine seedling/sapling composition (32-33\%), but damaged plots showed a higher percent of quaking aspen (Populus tremuloides) seedlings/saplings $(20 \%)$ relative to healthy stands $(7 \%)$. In addition, high-severity outbreaks more often had quaking aspen seedling/saplings present (50\% of plots) relative to nonattacked, low- and medium-severity outbreaks (12-17\% of plots). As aspen tends to be a shade-intolerant tree species (Messier et al., 1999), this finding is not unexpected. The remaining seedlings/saplings were comprised of other coniferous species, dominated by subalpine fir and Douglas fir. The presence of lodgepole pine seedlings, even in the absence of a fire event, is consistent with the findings of others, although the success and rate of growth of these seedlings may depend on light availability and soil moisture (Stuart et al., 1989; Astrup et al., 2008; Teste et al., 2011).

We also explored whether the rate of new vegetation recruitment was dependent on outbreak severity, which influences light availability. The number of seedlings and saplings showed no relationship with outbreak severity or with change in albedo. Outbreak severity, however, was found to be strongly positively related to the percent understory non-tree vegetation cover $(y=0.66 \times-7.32, R=0.72, p<0.01)$ (Fig. 6). Although understory non-tree vegetation can be expected to be masked by snow during winter months, this phenomenon may be affecting the summer albedo change signal. If we control for outbreak severity, we find that the increase in summer albedo was positively correlated with percent understory vegetation for high-severity outbreak sites $(y=0.0002 \times-0.0004, R=0.68, p<0.01)$ where understory vegetation is most abundant. As herbaceous vegetation 
typically has a higher albedo than bare, dry soil (McCaughey, 1987; Bourque et al., 1995; Gholz and Clark, 2002), the understory non-tree vegetation may be contributing to the change in summer albedo, at least for high-severity outbreaks. Additionally, the annual increase in MODIS albedo decreased strongly with an increasing number of live trees remaining after outbreak, for medium-severity outbreaks $(R=$ $-0.85, p<0.01)$. This finding suggests that, at least for medium-severity outbreaks, in addition to the percent tree mortality, the absolute number of live remaining trees is also important in determining the magnitude and persistence of the albedo response.

\section{Discussion}

One of the advances this study made was to utilize historical data to document how albedo changes with time since a MPB outbreak. Both Vanderhoof et al. (2013) and O'Halloran et al. (2012) expected an increase in albedo past $14-15 \mathrm{yr}$ post-outbreak (the limit of data utilized in both studies). This expectation was observed in this study, with change in albedo peaking 14-20 yr post-outbreak, presumably as snags fell and sapling/seedling re-establishment was still low and/or small. The timing of snag fall appears to be consistent with existing literature, which shows tree fall peaking after 10-15 yr (Mitchell and Preisler, 1998; Huggard and Lewis, 2007). Despite differences in the number of images used and the scale of the data, MODIS- and Landsat-derived albedo produced very similar patterns of albedo with time since disturbance (Fig. 2), adding confidence to the overall characterization of albedo changes following outbreak. Larger error intervals observed for the Landsat-derived change in albedo was a consequence of smaller sample sizes due to fewer images being used.

Our findings regarding change in winter albedo were quite similar to those documented by O'Halloran et al. (2012), who documented an increase in winter albedo of $0.06 \pm 0.03$ at $4 \mathrm{yr}$ post-outbreak and a local maximum increase of $0.08 \pm 0.03$ at $11 \mathrm{yr}$ post-outbreak. In comparison, we documented an increase in winter MODIS and Landsat albedo of $0.06 \pm 0.002$ and $0.06 \pm 0.02$, respectively, for $4-13 \mathrm{yr}$ postoutbreak, and an increase of $0.10 \pm 0.004$ and $0.12 \pm 0.02$, respectively, for winter MODIS and Landsat at 14-20 $\mathrm{yr}$ post-outbreak. Although a different approach was used, we can also compare our findings to those observed by Vanderhoof et al. (2013), where an increase in winter albedo of $0.03 \pm 0.01$ was observed for $4-13$ yr post-outbreak. In summer, although both changes were very small, we found an average increase in albedo of $0.005 \pm 0.001$ for $4-13 \mathrm{yr}$ postoutbreak, relative to an increase of $0.002 \pm 0.002$ observed by Vanderhoof et al. (2013). The consistently smaller change in albedo observed by Vanderhoof et al. (2013) can be attributed to that study's use of USFS ADS polygons for a landscape-scale analysis (change in albedo averaged across many pixels) (Vanderhoof et al., 2013). Although the USFS ADS data set is currently the most comprehensive spatial source of MPB outbreak dynamics in the United States, the data set tends to over estimate the area attacked (B. Howell, personal communication, 2013), leading to a dilution of the quantified change in albedo due to the inclusion of both attacked and non-attacked pixels, emphasizing the more regional impacts rather than the local responses specifically within areas of outbreak. Both this study and O'Halloran et al. (2012), in contrast, used a plot-based approach, in which change in albedo was derived from one or more specific (or point-based) locations.

Given that the magnitude of albedo change varies with outbreak severity (Fig. 3), it is logical to explore whether the rate of albedo recovery also varies with outbreak severity. Unfortunately accurate severity data (\% tree mortality) was lacking for the USFS ADS historical data as well as the dendroecological plots; thus we were unable to directly quantify this variation. We can, however, explore the role of regrowth mechanisms in increasing canopy cover, reducing the change in albedo relative to non-attacked stands. Persistence of albedo change or, alternatively, the forest recovery from epidemic MPB outbreaks in lodgepole pine tends to occur primarily through the reorganization of existing vegetation (e.g., advance regeneration), with existing understory trees and vegetation being released, in response to increased light, moisture and nutrients, to form the new canopy (Cole and Amman, 1980; Greene et al., 1999). The presence of understory trees and vegetation can limit the recruitment of new tree seedlings through competitive exclusion, sometimes limiting seedling establishment for many decades (Wickman et al., 1986; Wohlgemuth et al., 2002). This may explain the low seedling/sapling stem density observed at sites 1-20 yr post-outbreak. In stands with limited understory trees and vegetation, recovery via the establishment of new seedlings can still be highly variable due to varying site characteristics such as elevation, aspect, and soil type (Mitchell, 2005).

The primary regrowth mechanism to recover predisturbance albedo may also vary by outbreak severity. In low-severity outbreaks, we may expect that gaps in tree canopy will be primarily filled through the growth release and canopy expansion of remaining live canopy and subcanopy trees (Fig. 7). In high-severity outbreaks, it is likely that gaps will persist even after the growth release and canopy expansion of remaining live trees, due to (1) the limited capacity for the existing canopy to expand, and (2) the number of remaining live trees. In the case of moderate- and high-severity outbreaks, a full recovery of albedo will also require the recruitment and growth of new seedlings/saplings. If we assume that an increase in canopy cover due to the reorganization of existing vegetation will occur faster than due to the recruitment and growth of new vegetation (Griesbauer and Green, 2006), then the persistence of the change in albedo will depend on outbreak severity, which will in- 


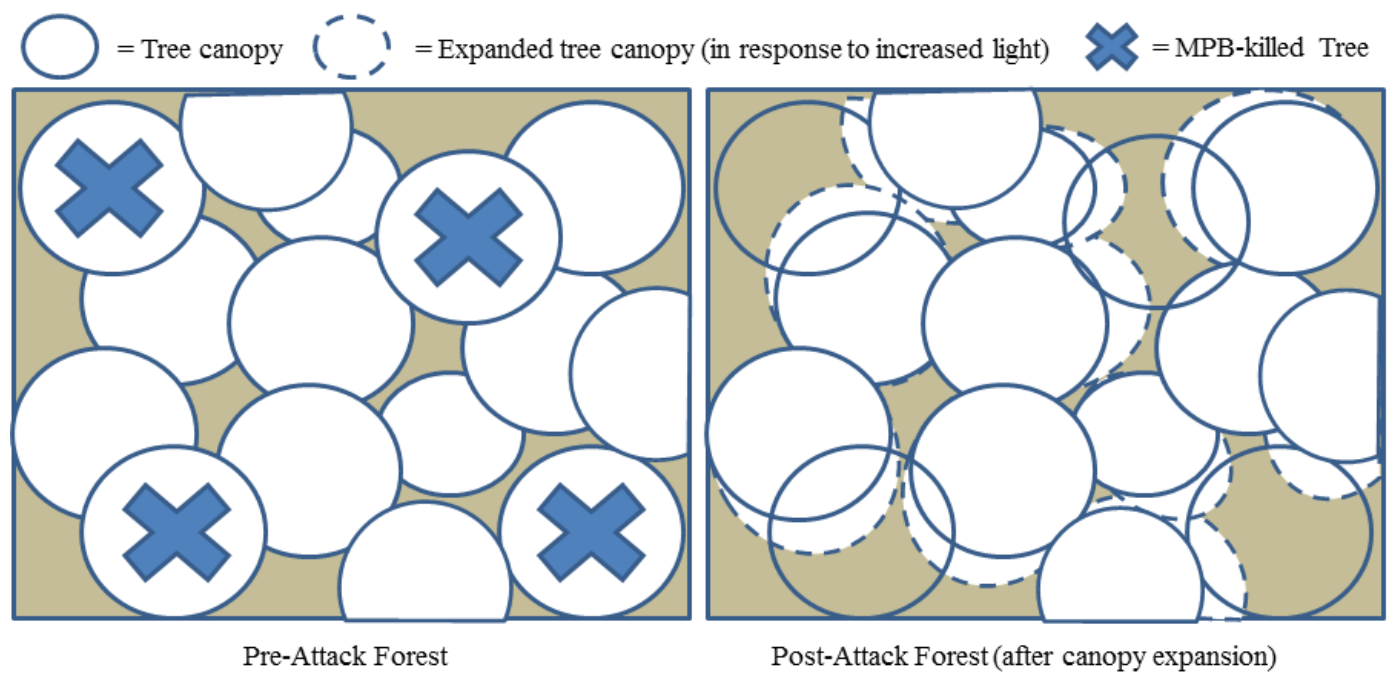

Fig. 7. Remaining canopy and subcanopy trees can be expected to expand in response to increased light availability post-MPB attack; however we can anticipate that the capacity of this expansion will be limited.

fluence the fractional contribution of each forest regrowth mechanism to albedo recovery (Fig. 8).

Secondarily, we may consider whether the growth rate of both existing and new vegetation depends on outbreak severity. Current literature shows that the growth release for existing vegetation is typically related to light availability, which will vary based on outbreak severity (Mitchell, 2005; Messier et al., 1999; McCarthy, 2001). However, even following high-severity outbreaks, standing snags will provide shade for approximately $15 \mathrm{yr}$ post-outbreak (Griesbauer and Green, 2006). In general, shade-tolerant species, such as Douglas fir, interior spruce (Picea glauca) and subalpine fir, tend to better utilize the gradual increases in light levels relative to shade-intolerant trees (e.g., lodgepole pine, ponderosa pine, quaking aspen, or paper birch (Betula papyrifera)) (Mitchell, 2005; Messier et al., 1999; McCarthy, 2001). In addition, shade-tolerant trees can adjust their crown physiology and structure in response to different light regimes, even after long periods of suppression, which makes them highly responsive to gradual increases in light following an outbreak (Messier et al., 1999; McCarthy, 2001). In contrast, shadeintolerant species tend to have more fixed crown physiology and structure, and thus are less able to respond with a strong growth release (Messier et al., 1999; Williams et al., 1999). These species-specific differences in growth release imply that Douglas fir and subalpine fir should play a substantial role in the recovery of the canopy if these species are present at a given site. Shade-intolerant species, however, may still do well on edaphically limiting sites (Williams et al., 1999) or sites with large canopy gaps (McCarthy, 2001).

Following high-severity outbreaks where light is less limiting, and in which we observed more frequent quaking aspen recruitment, the persistence of an albedo effect post-outbreak will also depend on the future species composition of the stand (coniferous versus deciduous). If the post-outbreak forest becomes dominated by deciduous trees, we might expect a prolonged persistence of winter change in albedo due to winter leaf loss and therefore increased visibility of snow, relative to coniferous stands. In high light conditions and where aspen clones are present, aspen's sprouting ability can lead to its dominance in early successional stages, before slower-growing lodgepole pine trees outcompete patches of aspen (Kaufmann et al., 2008). Using aerial imagery, we found that most historic outbreak sites showed strong establishment of coniferous saplings which eventually created a closed-canopy environment; however, one historical dendroecological plot (Kulakowski et al., 2012) showed a persistent increase in winter albedo at 40-50 yr post-outbreak, similar to the change observed at 20-30 yr post-outbreak at other historic outbreak sites, due to the establishment and/or shift in species composition towards deciduous tree species. This observation indicates that the temporal persistence found in this study depends on the initial regeneration of evergreen coniferous species post-outbreak, and that the establishment of deciduous species post-outbreak can increase the temporal persistence of the albedo impact by at least several decades (Randerson et al., 2006).

For new vegetation, we found a strong relationship between non-tree vegetation cover and percent tree mortality for recent outbreaks $(<14 \mathrm{yr})$ (Fig. 6), indicating that its establishment is influenced by light availability. We did not find a relationship between seeding/sapling recruitment and outbreak severity, for which there may be several explanations. Since seedling/sapling density data (unlike the percent understory vegetation) were derived from subplots $\left(25 \mathrm{~m}^{2}\right)$ within the larger tree plots $\left(900 \mathrm{~m}^{2}\right)$, the lack of correlation with outbreak severity may occur because the response or establishment of seedling/saplings is very local 


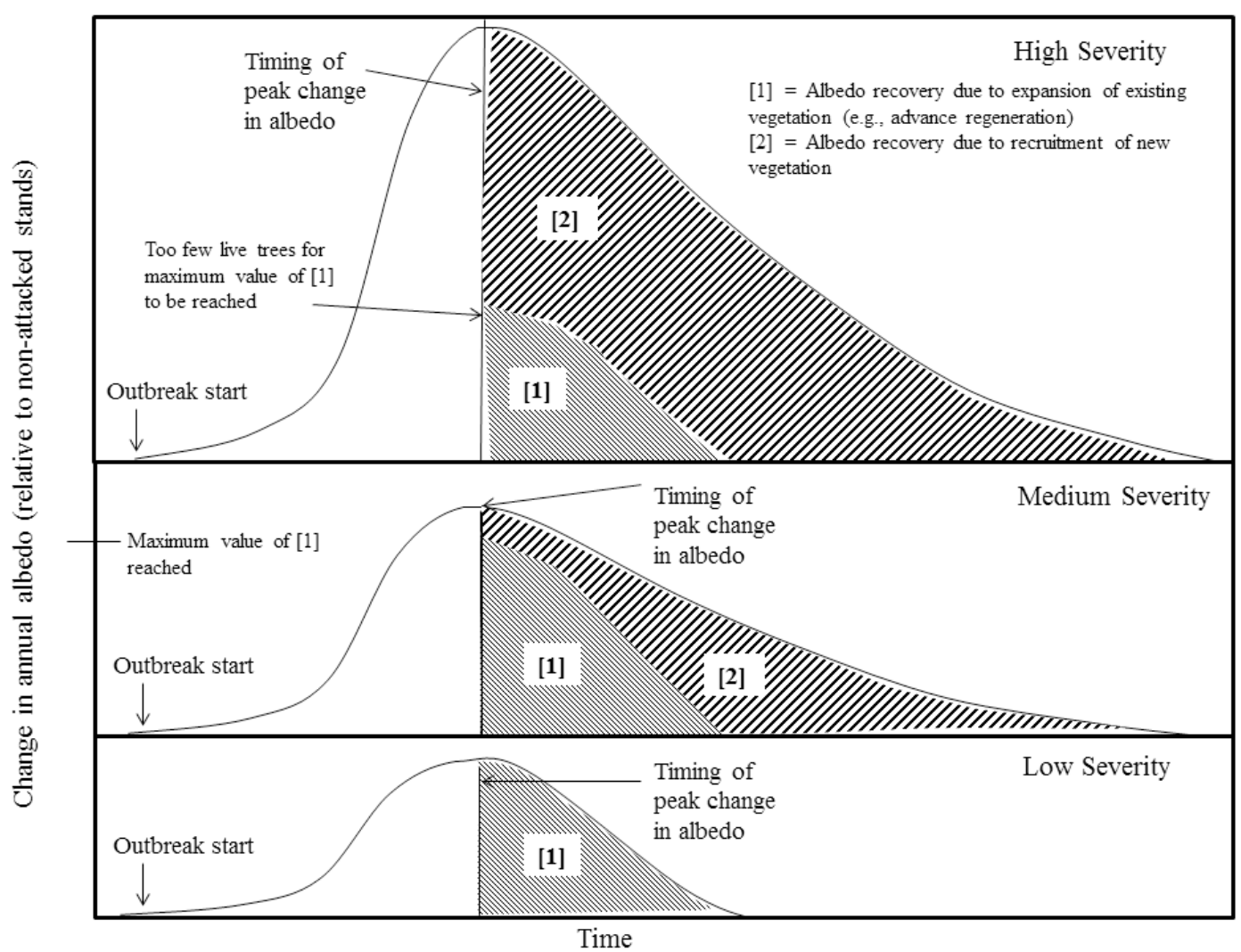

Fig. 8. The theoretical persistence of change to surface albedo due to outbreak severity and the resulting fractional contribution of each regrowth mechanism. It is assumed that an increase in canopy cover due to the expansion of existing vegetation will occur faster than due to the recruitment of new vegetation, but that some limit exists in the ability for existing vegetation to recover pre-attack canopy cover.

(at a tree scale), leading to a potential disconnect between the seedling/sapling density and the percent tree mortality observed at the plot scale. In addition, the lack of correlation may occur because not enough time since disturbance has passed to reflect the expected pulse of seedlings/saplings post-disturbance (Wickman et al., 1986; Wohlgemuth et al., 2002). No significant difference between seedling/sapling density was observed between non-attacked, 4-13 yr and 14$20 \mathrm{yr}$ since attack. A future research step could be to collect additional vegetation data within sites near the threshold of albedo recovery (20-40 yr post-outbreak) and correlate albedo change (or lack of albedo change, relative to nonattacked stands) with number of live mature trees, crown size of live trees, percent understory vegetation and number and size of saplings to directly determine the relative importance of factors to the persistence of albedo change post-MPB outbreak.

The magnitude of MPB-induced albedo-driven radiative forcing observed in this study agrees well with that reported by O'Halloran et al. (2012) (winter albedo radiative forcing of $-1.9 \pm 0.3 \mathrm{~W} \mathrm{~m}^{-2}$ at year four and $-2.4 \pm 0.4 \mathrm{~W} \mathrm{~m}^{-2}$ at year eleven). The long-term radiative forcing of MPB attacks can also be compared to the impact of forest fires, another disturbance type common to the south-central Rocky Mountains. The long-term albedo-driven radiative forcing of a severe fire event in boreal Alaska $\left(-4 \pm 2 \mathrm{~W} \mathrm{~m}^{-2}\right.$ for yr 0-80) reported by Randerson et al. (2006) was much higher than that of the long-term (4-30 yr) albedo-driven radiative forcing from a MPB outbreak (winter $=-2.1 \pm 0.3 \mathrm{~W} \mathrm{~m}^{-2}$; annual $=0.5 \pm 0.08 \mathrm{~W} \mathrm{~m}^{-2}$ ) as reported here. This is because of a larger increase in winter albedo post-fire (change of $\sim 0.4$ ) than that observed post-MPB outbreak (change of $\sim 0.1$ for $14-20$ yr post-outbreak). However direct comparison may not be warranted given the difference in species composition, snow-cover climatology, rates of regeneration, and other factors. Furthermore, the potentially smaller radiative cooling from MPB outbreaks may be somewhat compensated by the larger spatial extent of MPB outbreaks relative to fire within Colorado and southern Wyoming over the same time frame. Fire extent (as derived from MTBS data) was 396800 ha (all cover types) for 1994-2010 compared to 822200 ha of MPB outbreak (1994-2010) within lodgepole pine forests.

A full radiative forcing analysis for MPB outbreaks must also consider committed carbon emissions, based on total tree mortality. However it must be noted that while the albedo 
radiative forcing component will occur immediately, as will a reduction in net ecosystem carbon uptake due to a stand reduction in leaf area index and associated productivity, a substantial lag will occur before killed trees fully decompose (the committed $\mathrm{CO}_{2}$ emissions). The turnover time for lodgepole pine coarse woody debris in the Colorado Rocky Mountains can be on the order of hundreds of years, ranging from $340 \pm 130 \mathrm{yr}$ to $630 \pm 410 \mathrm{yr}$ depending on temperature (Brown et al., 1998; Kueppers et al., 2004). This time lag between albedo and carbon radiative forcing is important to recognize.

Lastly, we note that mountain pine beetle outbreaks have potential consequences for the hydrological cycle as well. Widespread tree mortality in mountain-pine-beetle-infested stands has been shown to result in earlier snowmelt, from increased canopy shortwave transmissions (Bewley et al., 2010; Pugh and Small, 2012), as well as increased stream flow, from a reduction in transpiration and canopy interception (Mikkelson et al., 2013). These changes could reduce water availability during the late growing season, exacerbating tree stress. Alternatively, the documented decrease in winter radiative forcing, due to increased snow visibility, could result in cooler wintertime air temperatures, potentially reducing beetle populations via winter "cold snaps" known to kill beetles.

\section{Conclusions}

Combining multiple data sets, both recent and historical, we quantified the cumulative radiative forcing due to MPB outbreaks in lodgepole pine stands in the south-central Rocky Mountains. This is the first comprehensive estimate of the total albedo-induced radiative forcing from MPB outbreaks of which we are aware, and it might be useful as a reference for other affected regions while recognizing likely variation with climate, edaphic, and biotic (species composition) factors. For MPB outbreaks in lodgepole pine stands in the south-central Rocky Mountains, albedo post-outbreak was consistently higher than in non-attacked stands from 4 to $30 \mathrm{yr}$ since the start of outbreak and then returned to preoutbreak levels. Seasonally, changes in albedo peaked during the winter season, with the increased visibility of snow, but significant differences in albedo, from non-attacked stands, were observed in all four seasons. Change in albedo also increased with increasing attack severity (\% tree mortality), particularly in the winter season. This variation translated into large differences in winter radiative forcing for gray attack stands $\left(0.2 \pm 0.03 \mathrm{~W} \mathrm{~m}^{-2}\right.$ for low-severity outbreaks versus $-2.3 \pm 0.3 \mathrm{~W} \mathrm{~m}^{-2}$ for high-severity outbreaks). The magnitude of albedo response in the first decade following attack depends on the number of remaining live trees, their species composition, the size of the growth release, and the establishment of understory vegetation. In the longer term, the persistence of albedo effects depends also on the rate of growth and species composition of subcanopy seedlings and saplings. Prior to recovery, the albedo-induced radiative forcing may create seasonally specific temperature and precipitation feedbacks, which may contribute to the persistence or reduction of MPB outbreaks in the coming decades.

Acknowledgements. This work was funded by the 2011-2013 NASA Earth and Space Science Fellowship (NESSF) (12Earth12R-59 and 13-Earth13R-8). Additional financial support was received from the NASA ROSES09 Science of Terra and Aqua program (grant \#: NNX11AG53G) as well as the National Science Foundation (grant \#: 1262691). We thank Rocky Mountain National Park for their field support and Marcus Pasay for his assistance with field work. We also thank Brian Howell and Justin Backsen of the USFS Region 2 for their assistance with the historical ADS surveys, as well as the anonymous reviewers for their helpful comments on previous versions of this paper.

Edited by: Y. Luo

\section{References}

Alfaro, R. I., Campbell, E., and Hawkes, B. C.: Historical frequency, intensity and extent of mountain pine beetle disturbance in British Columbia. Mountain Pine Beetle Working Paper 200930. Natural Resources Canada, Canadian Forest Service, Paci?c Forestry Centre, Victoria, BC, 2010.

Astrup, R., Coates, K. D., and Hall, E.: Recruitment limitation in forests: Lessons from an unprecedented mountain pine beetle epidemic, Forest Ecol. Manag., 256, 1743-1750, 2008.

Axelson, J. N., Alfaro, R. I., and Hawkes, B. C.: Influence of fire and mountain pine beetle on the dynamics of lodgepole pine stands in British Columbia, Canada, Forest Ecol. Manag., 257, 18741882, 2009.

Axelson, J. N., Alfaro, R. I., and Hawkes, B. C.: Changes in stand structure in uneven-aged lodgepole pine stands impacted by mountain pine beetle epidemics and fires in central British Columbia, The Forestry Chronicle, 86, 87-99, 2010.

Bala, G., Caldeira, K., Wickett, M., Phillips, T. J., Lobell, D. B., and Mirin, A.: Combined climate and carbon-cycle effects of largescale deforestation, P. Natl. Acad. Sci. USA, 104, 6550-6555, 2007.

Bentz, B., Logan, J., MacMahon, J., and Allen, C.: Bark Beetle Outbreaks in Western North America: Causes and Consequences, University of Utah Press, Chicago, IL, 2009.

Berg, E. E., Henry, J. D., Fastie, C. I., de Volder, A. D., and Matsuoka, S. M.: Spruce beetle outbreaks on the Kenai Peninsula, Alaska and Kluane National Park and Reserve, Yukon Territory: Relationship to summer temperatures and regional differences in disturbance regimes, Forest Ecol. Manag., 227, 219-232, 2006.

Bethlahmy, N.: More streamflow after a bark beetle epidemic, J. of Hydrology, 23, 185-189, 1974.

Betts, R. A.: Offset of the potential carbon sink from boreal forestation by decreases in surface albedo, Nature, 408, 187-190, 2000.

Bewley, D., Alila, Y., and Varhola, A.: Variability of snow water equivalent and snow energetic across a large catchment subject to Mountain Pine Beetle infestation and rapid salvage logging, J. of Hydrology, 388, 464-479, 2010. 
Boon, S.: Snow accumulation following forest disturbance, Ecohydrology, 5, 279-285, 2012.

Bourque, C. P. A., Daugharty, D. A., Dickinson, R. B. B., and Arp, P. A.: Changes in albedo of a northern hardwood forest following clearcutting, Forest Science, 41, 268-277, 1995.

Brown, P. M., Shepperd, W. D., Mata, S. A., and McClain, D. L.: Longevity of windthrown logs in a subalpine forest of central Colorado, Can. J. Forest Res., 28, 932-936, 1998.

Claussen, M., Brovkin, V., and Ganopolski, A.: Biogeophysical versus biogeochemical feedbacks of large-scale land cover change, Geophys. Res. Lett., 28, 1011-1014, 2001.

Clow, D. W., Rhoades, C., Briggs, J., Caldwell, M., and Lewis, W. M. J.: Responses of soil and water chemistry to mountain pine beetle induced tree mortality in Grand County, Colorado, Applied Geochemistry, 26, S174-S178, doi:10.1016/j.apgeochem.2011.03.096, 2011.

Collins, W. D., Rasch, P. J., Boville, B. A., Hack, J. J., McCaa, J. R., Williamson, D. L., and Briegleb, B. P.: The formulation and atmospheric simulation of the Community Atmosphere Model Version 3 (CAM3), J. Climate, 19, 2144-2161, 2006.

Cole, W. E. and Amman, G. D.: Mountain pine beetle dynamics in lodgepole pine forests: Part 1. Course of an infestation. U.S. Department of Agriculture Forest Service, Intermountain Research Station, Ogden, Utah. General Technical Report INT-89, 1980.

Eidenshink, J., Schwind, B., Brewer, K., Zhu, Z., Quayle, B., and Howard, S.: A project for monitoring tends in burn severity, Fire Ecology, 3, 3-21, 2007.

Gao, F., Schaaf, C. B. Strahler, A. H., Roesch, A., Lucht, W., and Dickinson, R.: MODIS bidirectional reflectance distribution function and albedo Climate Modeling Grid products and the variability of albedo for major global vegetation types, J. Geophys. Res., 110, 1-13, 2005.

Gholz, H. L. and Clark, K. L.: Energy exchange across a chronosequence of slash pine forests in Florida, Agr. Forest Meteorol., 112, 87-102, 2002.

Greene, D. F., Zasada, J. C., Sirois, L., Kneeshaw, D., Morin, H., Charron, I., and Simard, M. J.: A review of the regeneration dynamics of North American boreal forest tree species, Can. J. Forest Res., 29, 824-839, 1999.

Griesbauer, H. and Green, S.: Examining the utility of advance regeneration for reforestation and timber production in unsalvaged stands killed by the mountain pine beetle: Controlling factors and management implications, BC J. Ecosys. Manag., 7, 81-92, 2006.

Hall, D. K., Riggs, G. A., Salomonson, V. V., DiGiromamo, N., and Bayr, K. J.: MODIS Snow-Cover Products, Rem. Sens. Environ., 83, 181-194, 2002.

Hansen, J., Sato, M., and Ruedy, R.: Radiative forcing and climate response, J. Geophys. Res., 102, 6831-6864, doi:10.1029/96JD03436, 1997.

Heath, R. and Alfaro, R. I.: Growth response in a Douglas pine stand after thinning of lodgepole pine by the mountain pine beetle: A case study, J. Entomological Soc. BC, 87, 16-21, 1990.

Huggard, D. and Lewis, D.: Summary of: ECA Effects of Options for Mountain Pine Beetle Salvage - Stand and Watershed Level Reports, BC Ministry of Environment: Kamloops, Unpublished Report, 10 pp., 2007.

Intergovernmental Panel on Climate Change (IPCC): Good practice guidance and uncertainty management in national greenhouse gas inventories, edited by Penman, J., Kruger, D., and Galbally, I., Inst. for Global Environ. Strategies, Kanagawa, Japan, 2000.

Jarvis, D. and Kulakowski, D.: Is the extent of the current mountain pine beetle outbreak unprecedented?, in preparation, 2014.

Kaufmann M. R., Aplet, G. H., Babler, M., Baker, W. L., Bentz, B., Harrington, M., Hawkes, B. C., Huckaby, L. S., Jenkins, M. J., Kashian, D. M., Keane, R. E., Kulakowski, D., McHugh, C., Negron, J., Popp, J., Romme, W. H., Schoennagel, T., Shepperd, W., Smith, F. W., Kennedy Sutherland, E., Tinker, D., and Veblen, T. T.: The status of our scientific understanding of lodgepole pine and mountain pine beetles - a focus on forest ecology and fire behavior, The Nature Conservancy, Arlington, VA. GFI technical report 2008-2, 2008.

Klutsch, J. G., Negron, J. F., Costello, S. L., Rhoades, C. C., West, D. R., Popp, R., and Caissie, R.: Characteristics and downed woody debris accumulations associated with mountain pine beetle (Dendroctonus ponderosae Hopkins) outbreak in Colorado. Forest Ecol. Manag, 258, 641-649, 2009.

Kueppers, L. M., Southon, J., Baer, P., and Harte, J.: Dead wood biomass and turnover time, measured by radiocarbon along a subalpine elevation gradient, Oecologia, 141, 641-651, 2004.

Kulakowski, D. and Jarvis, D.: The influence of mountain pine beetle outbreaks on severe wildfires in northwestern Colorado and southern Wyoming: a look at the past century, Forest Ecol. Manag., 261, 1686-1696, 2011.

Kulakowski, D., Jarvis, D., Veblen, T. T., and Smith, J.: Standreplacing fires reduce susceptibility of lodgepole pine to mountain pine beetle outbreaks in Colorado, J. Biogeography, 39, 2052-2060, 2012.

Mäkinen H., Hynynen, J., Siitonen, J., and Sievänen, R.: Predicting the decomposition of Scots pine, Norway spruce, and birch stems in Finland, Ecol. App., 16, 1865-1879, 2006.

McCarthy, J.: Gap dynamics of forest trees: A review with particular attention to boreal forests, Environ. Rev., 9, 1-59, 2001.

McCaughey, J. H.: The albedo of a mature mixed forest and a clearcut site at Petawawa, Ontario, Agr. Forest Meteorol., 40, 251263, 1987.

Messier, C., Doucet, R., Ruel, J., Claveau, Y., Kelly, C., and Lechowicz, M. J.: Functional ecology of advance regeneration in relation to light in boreal forests, Can. J. Forest Res., 29, 812823, 1999.

Mikkelson, K. M., Maxwell, R. M., Ferguson, I., Stednick, J. D., McCray, J. E., and Sharp, J. O.: Mountain pine beetle infestation impacts: modeling water and energy budgets at the hill-slope scale, Ecohydrology, 6, 64-72, 2013.

Mitchell, J.: Review and synthesis of regeneration methods in beetle-killed stands following mountain pine beetle (Dendroctonus ponderosae) attack: A literature review. Natural Resources Canada, Canadian Forest Service, Paci?c Forestry Centre, Victoria, B.C. Mountain Pine Beetle Initiative Working Paper 20052016, 2005.

Mitchell, R. G. and Preisler, H. K.: Fall rate of lodgepole pine killed by the mountain pine beetle in central Oregon, West. J. Applied Forestry, 13, 23-26, 1998.

Naesset, E.: Decomposition rate constants of Picea abies logs in southeastern Norway. Can. J. Forest Res., 29, 372-381, 1999. O'Halloran, T. L., Law, B. E., Goulden, M. L., Wang, Z., Barr, J. G., Schaaf, C., Brown, M., Fuentes, J. D., G?ckede, M., Black, 
A., and Engel, V.: Radiative forcing of natural forest disturbances, Glob. Change Biol., 18, 555-565, 2012.

Potts, D. F.: Hydrologic impacts of a large scale mountain pine beetle (Dendroctonus ponderosae Hopkins) epidemic, Water Res. Bull., 20, 373-377, 1984.

Pugh, E. and Small, E.: The impact of pine beetle infestation on snow accumulation and melt in the headwaters of the Colorado River, Ecohydrology, 5, 467-477, 2012.

Raffa, K. F., Aukema, B. H., Bentz, B. J., Carroll, A. L., Hicke, J. A., Turner, M. G., and Romme, W. H.: Cross-scale drivers of natural disturbances prone to anthropogenic amplification: the dynamics of bark beetle eruptions, BioScience, 58, 501-517, 2008.

Randerson, J. T., Liu, H., Flanner, M. G., Chambers, S. D., Jin, Y., Hess, P. G., Pfister, G., Mack, M. C., Treseder, K. K., Welp, L. R., Chapin, F. S., Harden, J. W., Goulden, M. L., Lyons, E., Neff, J. C., Schuur, E. A. G., and Zender, C. S.: The impact of boreal forest fire on climate warming, Science, 314, 1130-1132, 2006.

Roman, M. O., Schaaf, C. B., Woodcock, C. E., Strahler, A. H., Yang, X., Braswell, R. H., Curtis, P. S., Davis, K. J., Dragoni, D., Goulden, M. L., Gu, L., Hollinger, D. Y., Kolb, T. E., Meyers, T. P., Munger, J. W., Privette, J. L., Richardon, A. D., Wilson, T. B., and Wofsy, S. C.: The MODIS (Collection V005) BRDF/albedo product: assessment of spatial representativeness over forested landscapes, Rem. Sens. Environ., 113, 2476-2498, 2009.

Schaaf, C. B., Gao, F., Strahler, A. H., Lucht, W., Li, X., Tsang, T., Strugnell, N. C., Zhange, X., Jin, Y., Muller, J. P., Lewis, P., Barnsley, M., Hobson, P., Disney, M., Roberts, G., Dunderdale, M., Doll, C., d'Entremont, R. P., Hu, B., Liang, S., Privett, J. L., and Roy, D.: First operational BRDF, albedo nadir reflectance products from MODIS, Rem. Sens. Environ., 83, 135-148, 2002.

Shell, K. M., Kiehl, J. T., and Shields, C. A.: Using the radiative kernel technique to calculate climate feedbacks in NCAR's Community Atmospheric Model, J. Clim., 21, 2269-2282, 2008.

Shuai , Y., Masek, J. G., Gao, F., and Schaff, C. B.: Algorithm for the retrieval of 30-m snow-free albedo from Landsat surface reflectance and MODIS BRDF, Rem. Sens. Environ., 115, 22042216, 2011.

Soden, B. J., Held, I. M., Colman, R., Shell, K. M., Kiehl, J. T., and Shields, C. A.: Quantifying climate feedbacks using radiative kernels, J. Clim., 21, 3504-3520, 2008.

Spracklen, D. V., Bonn, B., and Carslaw, K. S.: Boreal forests, aerosols and the impacts on clouds and climate, Philos. Trans. Royal Soc. A., 366, 4613-4626, 2008.
Stuart, J. D., Agee, J. K., and Gara, R. I.: Lodgepole pine regeneration in an old, self-perpetuating forest in south central Oregon, Can. J. Forest Res., 19, 1096-1104, 1989.

Teste, F. P., Lieffers, V. J., and Landhäusser, S. M.: Seed release in serotinous lodgepole pine forests after mountain pine beetle outbreak, Ecol. Appl., 21, 150-162, 2011.

United States Forest Service (USDA): Western bark beetle strategy, USDA Forest Service, 2011.

Vanderhoof, M., Williams, C. A., Ghimire, B., and Rogan, J.: Impact of mountain pine beetle outbreaks on forest albedo and TOA radiative forcing, as derived from Moderate Resolution Imaging Spectroradiometer, Rocky Mountains, USA, J. Geophys. Res. Biogeosciences, 118, 1-11, doi:10.1002/jgrg.20120, 2013.

Wang, K., Liang, S., Schaaf, C. L., and Strahler, A. H.: Evaluation of Moderate Resolution Imaging Spectroradiometer land surface visible and shortwave albedo products at FLUXNET sites, J. Geophys. Res.-Atmos., 115, 17107, doi:10.1029/2009JD013101, 2010.

Wickman, B. E., Seidel, K. W., and Starr, G. L.: Natural regeneration 10 years after a Douglas-?r tussock moth outbreak in northeastern Oregon, US Department of Agriculture Forest Service, Pacific Northwest Research Station, Portland, Oregon. Research Paper pnwrp-370, 1986.

Williams, H., Messier, C., and Kneeshaw, D. D.: Effects of light availability and sapling size on the growth and crown morphology of understory Douglas-fir and lodgepole pine, Can. J. Forest Res., 29, 222-231, 1999.

Winkler, R., Boon, S., Zimonick, B., and Baleshta, K.: Assessing the effects of post-pine beetle forest litter on snow albedo, Hydrol. Process., 24, 803-812, 2010.

Wohlgemuth, T., Kull, P., and Wuthrich, H.: Disturbance of microsites and early tree regeneration after windthrow in Swiss mountain forests due to the winter storm Vivian 1990. Forest and Snow Landscape Res., 77, 17-47, 2002.

Zhang, Y. C., Rossow, W. B., and Lacis, A. A.: Calculation of surface and top of atmosphere radiative fluxes from physical quantities based on ISCCP data sets: 1. Method and sensitivity to input data uncertainties, J. Geophys. Res., 100, 1149-1165, 1995. 